\title{
Aproximaciones a la temprana formación cívica de niños y niñas
}

\author{
Primeras publicaciones dirigidas a la niñez mexicana (1839-1843)
}

\author{
María Esther Aguirre LorA*
}

Entre los eventos más significativos que la modernidad impulsó está el auge de la cultura escrita/impresa, cuya consolidación en el curso del siglo XIX trajo consigo nuevas prácticas culturales que modificarían sustancialmente la forma de entender el mundo y de comunicarse con el otro, y que revelarían una gran diversidad de prácticas lectoras y de materiales. El siglo XIX comenzó a dirigirse a diversos tipos específicos de población; en este contexto surgieron El Diario de los Niños (1839-1840) y Los niños pintados por ellos mismos (1843), ambas publicaciones debidas a la iniciativa de Vicente García Torres, con el propósito de contribuir a la formación de los futuros ciudadanos que el nuevo proyecto de sociedad requería. Este texto estudia dichas publicaciones a través de los siguientes ejes: a) la primera publicación periódica dirigida a la niñez; b) modelos ejemplares o Mozart para niños; c) representaciones sociales en torno a la niñez.

The rise of written / printed culture is, without question, one of the most significant events set forth by the beginning of Modernity. Consolidated throughout the 19th century, it brought about a series of new cultural practices that would substantially modify the way we understand the world and communicate with the other, while also providing us with a great diversity of reading practices and materials. During the 19th century, the written word began to address various specific types of population; such is the case of Diario de los Niños (1839-1840) and Los niños pintados por ellos mismos (1843) periodical publications for children which emerged under the initiative of Vicente Garcia Torres, with the objective of contributing to the education of the future citizens required by the new project of society. This text studies these publications through the following axes: a) the first periodical publication aimed at children; b) exemplary models or Mozart for children; c) social representations around childhood.

Palabras clave

Modernidad

Cultura escrita/impresa

Prácticas culturales

Infancia

Modelos ejemplares

Keywords

Modernity

Written/printed culture

Cultural practices

Childhood

Exemplary models

Recepción: 22 de marzo de 2021 | Aceptación: 12 de septiembre de 2021

DOI: https://doi.org/10.22201/iisue.24486167e.2022.175.60407

* Investigadora titular en el Instituto de Investigaciones sobre la Universidad y la Educación (IISUE) de la Universidad Nacional Autónoma de México (UNAM) (México). Doctora en Pedagogía. Líneas de investigación: la nueva historia de la educación (contextos, temas, debates); historia social y cultural de la formación artística. Publicaciones recientes: (2021, coord.), Desplazamientos. Historia, educación, cultura, México, UNAM-IISUE; (2020), Pioneros de las ciencias y las artes. Travesías culturales entre la península itálica y la Nueva España, siglos XVI al XVIII, México, UNAM-IISUE. CE: mariaesthraguirre@gmail.com 
Cada generación está circundada de un particular paisaje de objetos que definen una época, gracias a las pátinas, a los signos y al aroma del tiempo de su nacimiento y de sus transformaciones. A su modo los objetos crecen y se desintegran, como los vegetales o los animales, se cargan de años y de siglos, vienen sustituidos, cuidados o descuidados, olvidados y destruidos.

R. BODEI.

\section{INTRODUCCIÓN ${ }^{1}$}

Hemos entrado de lleno en el universo de la cultura escrita/impresa desde el terreno de la historia cultural (Rioux y Sirinelli, 1999; Chartier, 2005a; Chartier, 2005b; Burke, 2006), ${ }^{2}$ donde ya no bastan los datos estadísticos en torno a las poblaciones alfabetizadas y no alfabetizadas, sino que hay que hilar fino para visibilizar filones inéditos en estos espacios (Cardona, 1994). En este variopinto universo, al lado del libro, desde el siglo XVIII comenzaron a cobrar relevancia distintos tipos de impresos que aportaban recursos a los libreros e impresores para poder subsistir en el oficio y que permitían, además, la formación de distintos tipos de lectores. Las publicaciones periódicas cobraban cada vez mayor importancia, dirigidas a distintos sectores de la población decimonónica que, al calor de los movimientos independentistas, dirigían sus esfuerzos, en la medida de sus posibilidades y de su impacto, a formar una ciudadanía instruida que favoreciera el progreso de la nación: lectora, civilizada, consciente de sus deberes. La cultura impresa sería una de las vías privilegiadas para la construcción de un proyecto republicano que concretaría formas renovadas de gobierno de las poblaciones modernas (Pérez Vejo, 2001).

En este contexto, en años recientes, el enriquecimiento de los repositorios y la mayor conciencia del valor de los diversos tipos de publicaciones periódicas que forman parte del mundo de la cultura escrita han hecho que las revistas sean consideradas como uno de los recursos más sugerentes para la investigación en el campo de la historia de la educación. Éstas pueden leerse desde distintas perspectivas y niveles de análisis, y a la vuelta de unos años han sido propicias para instituir líneas de investigación muy promisorias en relación con el estudio de la prensa en México. Pueden rastrearse a partir los trabajos pioneros de María del Carmen Ruiz Castañeda y Luis Reed (1974) hasta la reciente colección de catálogos publicados por el Instituto de Investigaciones Bibliográficas de la UNAM (Castro y Curiel, 2000), así como las aportaciones especializadas que surgen del Seminario Interdisciplinario de Bibliología, con sede en el mismo Instituto, entre otros.

Ahora bien, para el propósito de este texto es importante destacar que, si bien el universo de las publicaciones pronto comenzó a diferenciarse de acuerdo con la población a la que se dirigían, a mediados del siglo XIX las ediciones mexicanas ya habían logrado avances significativos, aunque resulta importante no perder de vista que la primera mitad de ese siglo estuvo imbuida en un panorama político muy conflictuado, lo cual dificultaba aún más el trabajo de editores e impresores. A la publicación de libros se sumó la atención a la impresión de publicaciones periódicas, que darían cuenta de algunos aspectos de las preocupaciones y la vida cotidiana de los sectores acomodados. También se editaron las conocidas revistas para mujeres, como la de Concepción Gimeno de Flacquer, El álbum de la mujer (1883-1890) y la de Laureana Wright y Mateana Murguía, Violetas del Anáhuac. Periódico literario redactado por Señoras (18871889), así como iniciativas dirigidas a otros sectores particulares de la población, como

\footnotetext{
${ }^{1}$ El antecedente de este artículo es Aguirre y Mier (2015).

2 Estamos de acuerdo con Rioux y Sirinelli (1999: 21), quienes atribuyen a la historia cultural "el estudio de las formas de representación del mundo dentro de un grupo humano cuya naturaleza puede variar —nacional, regional, social o política- y que analiza la gestación, la expresión y la transmisión... Un mundo legado por las transmisiones debidas al medio, a la educación, a la instrucción".
} 
era el caso de los trabajadores y artesanos, los artistas, actores y músicos, los maestros, y los niños (Castro y Curiel, 2000; Castañeda, 2002; Suárez de la Torre, 2003).

Es precisamente en este contexto en el que surge en México la primera publicación periódica que buscaba como público a los lectores más jóvenes, el Diario de los Niños $(D N),{ }^{3}$ editado de 1839 a $1840 ;{ }^{4}$ ésta coincide con la edición de otra publicación, Los niños pintados por ellos mismos (1843), ambas debidas a la iniciativa del mismo editor, Vicente García Torres, en los mismos años, lo cual resulta ampliamente significativo. El propósito de este artículo es aproximarse a las dos facetas complementarias, desde nuestro punto de vista, que tales publicaciones nos ofrecen. Por un lado, el $D N$, a través del tratamiento de las biografías de reconocidos personajes de la historia universal y de la cultura, expresa algunos de los modelos que se les ofrecían a los niños a través de narrativas que anticipan lo que posteriormente será la historia de la historia a través de biografías ejemplares (historia de bronce, con la consabida división entre los buenos y los malos, de inspiración rankeana); y Los niños pintados por ellos mismos ${ }^{5}$ nos aproxima a algunas de las formas en que la sociedad de la época representaba a la niñez, población sobre la que se quería influir.

\section{EL HORIZONTE}

Sabemos que los círculos ilustrados del México de las primeras décadas del siglo XIX experimentarían de lleno la necesidad de inscribirse en el programa político-cultural de la modernidad al transitar hacia una perspectiva de vida secularizada, orientada por la idea de progreso material, donde la igualdad de todos ante la ley y la gestión de la vida social por el Estado fueran propicios al bienestar individual y social. Las expectativas estaban puestas en el desarrollo de los programas civilizatorios que favorecerían la emergencia de los nuevos ciudadanos que requería la nueva sociedad y que pudieran estar a la altura de las naciones más avanzadas del orbe. Se trataba de poner la mira en hacer de los pobladores sujetos disciplinados, trabajadores y obedientes para conformar la comunidad cívica que se pretendía formar; esta comunidad tendería a la integración política y social a través de su inclusión en el proyecto de una república civilizada, regulada por leyes e instituciones que normalizarían las diferencias de origen racial, lo cual implicaba también cierto pulimento en la convivencia de unos con otros, y para ello se debía conocer el código de deberes y derechos.

El asunto, sin embargo, pronto reveló otras exigencias acordes con la mentalidad ilustrada de la época: hacer de niños y jóvenes, de acuerdo con el concepto elástico de infancia que prevalecía, nuevos ciudadanos que fueran personas cultivadas, informadas, con amplios horizontes culturales.

Todo ello es revelador, a su vez, de las embestidas modernizadoras que acontecieron en lo social, en lo económico y en lo cultural, desde las cuales es posible identificar las exigencias que se le planteaban al ciudadano y la necesidad de nuevas instancias para construirlo como tal.

Al respecto, la instrucción, en diferentes ámbitos y niveles, se vería como el medio idóneo para alcanzar los fines ambicionados; sin embargo, las cosas no marcharon del mejor modo, pues a la vuelta de pocos años las luchas por el poder y la falta de recursos harían

\footnotetext{
${ }^{3}$ En adelante nos referiremos a la publicación como $D N$.

4 Al respecto, es importante señalar que a partir de los años ochenta la atención se ha dirigido a lo que pudiéramos considerar "prensa infantil" (Camarillo y Lombardo, 1984; Galván, 1998; Alcubierre, 2005; Mondragón, 2008; Agostini, 2015) con el estudio de revistas procedentes de sectores liberales y conservadores dirigidas, por múltiples motivos, a sectores ilustrados, a la naciente burguesía urbana, con excepción de El Obrero del Porvenir (1870), ocupado en otro sector social.

5 En adelante nos referiremos a la publicación como NP.
} 
ver que el beneficio de las primeras letras y el acceso a las escuelas y los libros tardarían mucho en llegar al pueblo.

El porcentaje de alfabetizados era bajísimo. Si bien Meneses Morales anticipa la escasez, dispersión e imprecisión de los datos (Meneses, 1983), se sabe que en los inicios de la Independencia los porcentajes de analfabetismo eran exorbitantes: 99.38 por ciento frente a 0.6 por ciento de población alfabeta. Los periódicos de los años más próximos a la edición del $D N$ ofrecen un panorama nada estimulante:

...la instrucción primaria se ha visto hasta ahora, si no con abandono, con poquísimo empeño. A la fecha se ignora el número de escuelas existentes en la república, y nadie puede fiarse de las estadísticas anteriores. Nadie ha sufrido tanto como esta clase de establecimientos en los últimos años que, en vez de progresar, disminuyeron a la mitad (Meneses, 1983: 848).

Aunque habría que hilar más fino en la transición de la perspectiva del analfabetismo a la de la cultura escrita/impresa, ${ }^{6}$ surge, de entrada, una interrogante: ¿qué quiere decir todo esto en relación con la publicación del $D N$ ? Por principio de cuentas, había una distancia abismal entre las instituciones formativas propias de las élites y los otros sectores sociales: el porcentaje de niños alfabetizados era mínimo y aún más reducido el número de posibles lectores del $D N$, cuyo tiraje ignoramos. Los niños procedentes de los sectores populares, en el caso de que hubieran sobrevivido a sus precarias condiciones, en el mejor de los casos eran aprendices de algún artesano o bien se dedicaban a la vagancia o a la mendicidad (Sánchez, 2003).

En este contexto, no podemos desconocer que la prensa infantil, más allá de su impacto directo sobre el público de lectores cautivos, permite aproximarnos a las imágenes y expectativas que un grupo social tiene de sí mismo, a los valores y comportamientos que privilegia sobre otros y a la manera en que contribuye a formar un "nosotros" colectivo. El DN se inscribe en el conjunto de búsquedas de la época cuya apuesta era la construcción del proyecto político republicano, como ya mencionamos.

\section{LA PRIMERA PUBLICACIÓN PERIÓDICA DIRIGIDA A LA NIÑEZ}

La primera revista dirigida a los lectores más jóvenes, el Diario de los Niños, editado en las primeras décadas del siglo XIX, al distanciarse de otras publicaciones infantiles, como lo eran los catecismos y las cartillas, se constituyó en la primera publicación mexicana moderna dirigida a la niñez, vista ésta como una etapa de la vida con sus propias posibilidades y requerimientos, que empezaría a visibilizarse y a tener peso por sí misma. Y ése fue su mérito: con el paso del tiempo se añadirán otras publicaciones como El Ángel de los Niños (1861), El Ángel de la Guarda (1870-1871), La Enseñanza (1870-1876), El Álbum de los Niños (1870-1876), El Correo de los Niños (1872-1883), La Edad Feliz (1873), La Niñez Ilustrada (18731875) y Biblioteca de los Niños (1874-1876), entre otras editadas en la capital del país, a las que se añaden las editadas en los estados de la República. El Obrero del Porvenir (1870) constituyó

\footnotetext{
${ }^{6}$ Antes de los años ochenta del siglo XX, los estudios sobre la posibilidad de leer y escribir privilegiaron la perspectiva del alfabetismo versus el analfabetismo, legitimándose en los referentes estadísticos; hacia los años ochenta se abrió un fecundo diálogo interdisciplinar y se pasó a una visión más compleja del problema de la cual emergería el concepto de cultura escrita; este concepto se abrió a la perspectiva del sujeto y a la comprensión de los usos y del impacto de los sistemas de comunicación (Cardona, 1994). A partir de ahí, como señala Antonio Castillo, "Superada la connotación estadística de las primeras publicaciones sobre el alfabetismo, a principios de los ochenta los tiempos, como decía G.R. Cardona, estaban maduros para una especialización que tuviera por objeto los aspectos antropológicos y sociológicos del uso de los sistemas de comunicación gráfica. Lo que había nacido como historia del alfabetismo se estaba convirtiendo progresivamente en una investigación sobre el proceso de la alfabetización (o alfabetizaciones), sus agentes, modos y vías, la difusión de la mentalidad letrada, las funciones y usos de la escritura y la lectura, los contextos y prácticas de difusión y recepción de lo escrito, las relaciones entre la cultura oral y la cultura escrita, etc." (Castillo, 1995: 213).
} 
un caso aparte porque se dirigía a la niñez desvalida, procedente de los sectores obreros (Camarillo y Lombardo, 1984).

El $D N$ se publicó en la Ciudad de México de 1839 a 1840, en la imprenta de Miguel González, y en 1840, en la de Vicente García Torres. Su director fue Juan Wenceslao Sánchez de la Barquera. Planteado con una periodicidad semanal, en un tamaño de 17 x $26 \mathrm{~cm}$ y publicado en cuadernos de tres pliegos, tenía un costo de 2 reales en la capital y 3 reales fuera de ella, lo que permitiría su exigua sobrevivencia financiera ("Prospecto", en Diario de los Niños, I, 1839).

Figura 1. Primera portada del Diario de los Niños, 1839

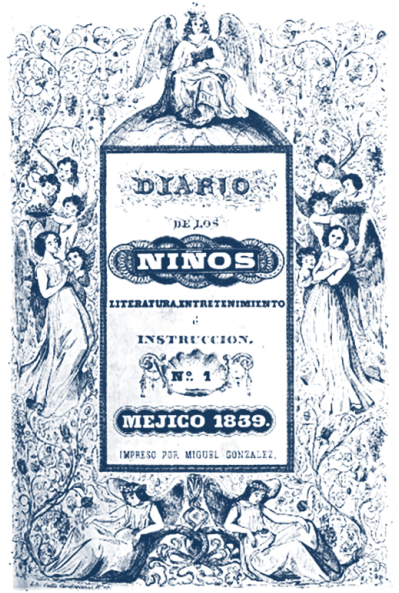

Fuente: Diario de los niños. Literatura, entretenimiento e instrucción, vol. I, 1839, México, Imprenta de Miguel González, en: http://hndm.unam.mx

El $D N$ se publicó en un momento particular del siglo XIX, década cercana al movimiento independentista novohispano, aún signada por el optimismo de algunos logros y expectativas de construcción del país. Los movimientos imperantes en México gravitaban en torno a apartarse de la influencia española y a la adopción de las ideas ilustradas que permitirían el progreso de México para colocarse a la altura de las naciones civilizadas. Así que Francia era un buen ejemplo a seguir para el nuevo Estado, no sólo en términos de su proceso de constitución, sino también en la forma de preparar a los futuros ciudadanos. La formación que Vicente García Torres, editor del $D N$, recibió en el país galo le avivó el deseo de introducir este tipo de publicaciones dirigidas a los niños. En contraste con la magnitud del proyecto editorial que se proponía estaba la recurrente constatación de falta de recursos, indicio de las circunstancias locales que limitaban la difusión del Diario de los Niños. Si tomamos en cuenta que iba dirigido a un público lector formado por niños y adolescentes cuyas edades oscilarían entre los 7 y 14 años, así como a aquellos que estaban cercanos a la niñez - padres de familia y maestros $-{ }^{7}$ podemos ver que la difusión del $D N$ quedaba circunscrita a una pequeña porción de ese 0.6 por ciento de mexicanos alfabetizados. Así, aunque los propósitos de Vicente García Torres y Juan Wenceslao Sánchez de la Barquera eran menos elitistas que los de sus homólogos franceses, la circulación del $D N$ debe haberse limitado a los círculos que ya se nutrían del mundo de la cultura escrita.

Si bien uno de los propósitos de los editores era "proteger las ciencias y las artes del país" ("Prospecto", 1839: 3), las propias circunstancias del momento -que volvían difícil un proyecto cultural de este tipo- obligaban a recurrir tanto a la publicación de textos españoles como a la traducción de otros franceses e ingleses; en el caso específico que nos ocupa, la referencia fue la traducción parcial y la adaptación al español de Le Journal des Enfants (París, 1832); en ella, a algunos de los textos traducidos del francés se agregaron otros traducidos del inglés y otros más procedentes de los diarios europeos en circulación. ${ }^{8}$ Los editores son conscientes de ello; nos dicen:

\footnotetext{
Con referencia al posible público adulto, las publicaciones homólogas en Francia contaban "une partie 'annonces' consistant en des offres ou demandes d'emploi pour les institutrices" (Thirion, 1972: 7).

8 "Con intenciones eminentemente pedagógicas, el $D N$ se perfiló desde sus orígenes como una miscelánea instructiva dirigida a la juventud y a la niñez mexicanas; es una traducción parcial de la obra del mismo nombre editada
} 
"al publicar el primer número de nuestro periódico... sólo tendremos el mérito de la traducción" ("Prólogo", en Diario de los Niños, I, 1839: 1). El propósito de Le Journal, modelo del mexicano, era "Instruire et moraliser tout en amusant telle est la devise que nous avons choisie" (Thirion, 1972: 9). ${ }^{9}$ Proyectos como Le Journal des Enfants (1832), Le Magasine des Enfants (1834-1838) o Le Petit Messager (1833-1834) tenían el propósito de:

...mettre entre les mains de leurs enfants un recueil périodique qui les intéresse et développe en eux les qualités intellectuelles par l'enseignement de l'histoire, de la littérature et des sciences, qui agrandisse leur âme par les sublimes vérités de la religion et forme leur cour à la pratique des vertus qui font le citoyen et le chrétien modèle (Thirion, 1972: 10).

El Diario de los Niños es, además, indicio del despliegue del mundo editorial posible en aquellos años: los avances en el arte de la impresión se traslucen en la introducción de algunas cromolitografías y grabados en blanco y negro. Para entonces su impresor, Víctor García Torres (1811-1894), recién iniciaba su carrera como tal (Nava, 2002) y en poco tiempo formaría parte de la comunidad de editores más reconocida en nuestro país..$^{10}$ Cabe destacar que, además de su valiosa y versátil producción editorial, fue uno de los intelectuales del siglo XIX más comprometidos con las causas del liberalismo en el país.

Lo anterior se comprende a partir del director Juan Wenceslao Sánchez de la Barquera
(1779-1840) quien, con estudios de latinidad, filosofía y jurisprudencia, profundamente comprometido con los procesos independentistas, editó el Diario de México de 1806 a 1810, escabullendo, a través de distintos subterfugios, a los poderes virreinales e inquisitoriales. Años después, en 1825, como síndico del Ayuntamiento, promovió que se celebrara el 16 de septiembre como fiesta oficial y se instituyera un templo dedicado a las funciones cívicas ("Juan Wenceslao Sánchez de la Barquera”, 1910). En esta situación resulta claro su propósito de editar una publicación periódica dirigida a los niños, ciudadanos en formación, que, si bien surge de la homónima francesa publicada en París, no hace gran diferencia respecto de las revistas de la época dirigidas a otros públicos. Sin embargo, el proyecto de los editores deseaba ir más allá:

...no nos limitaremos a traducir el Diario de los Niños solamente; copiaremos cuanto en los periódicos ingleses sea análogo a nuestro objeto; tomaremos de las mejores obras cuanto sea digno de presentarse a nuestros conciudadanos, y tendrá un lugar en nuestras columnas lo útil y lo agradable, sea cual fuere su origen (Diario de los Niños, I, 1839: 1).

De este modo, Sánchez de la Barquera enfrentaba la difícil tarea de darle rostro a la publicación mexicana. La efervescencia política y su propio compromiso con el proyecto de república que se estaba construyendo a partir de modelos europeos, inducía a la sociedad a crear sus propias imágenes, incluida

en París. Publicó reproducciones en español de artículos aparecidos en periódicos europeos como el Panorama Matritense, el Indicatore di Milano y El Español, así como secciones dedicadas a cuestiones que atañen exclusivamente a México. El Diario agrega en su parte literaria la traducción de fragmentos de la obra de Washington Irving, Fenelón y Buffon, además de una selección de poetas españoles entre los que destacan Espronceda y García y Tassara; por otro lado, a manera de complemento a las partes de recopilación y traducción, aparecieron las colaboraciones referentes a temas de carácter nacional" (Castro y Curiel, 2000: 130).

9 Para un panorama más completo del desarrollo de la prensa infantil en Francia puede consultarse Nières-Chevrel, 2010. Asimismo, para un cuadro más completo de los sucesos políticos y sociales que tuvieron lugar en Francia durante el complicado periodo entre 1815 y 1848, ver Briggs y Clavin, 1997.

${ }^{10}$ Nos referimos al grupo integrado por José María Andrade, Ignacio Cumplido (1811-1887), José Mariano Fernández de Lara, Mariano Galván Rivera (1782-1876) y Rafael de Rafael (1817-1882). García Torres tuvo una rica y diversificada producción editorial cuya madurez se expresa la edición de El Monitor Republicano, que junto con El Siglo XIX, fue uno de los diarios liberales más importantes del México decimonónico. 
la imagen cultural de la infancia, como ya lo señalamos, con la preocupación expresa de contribuir a la forja de la patria y reconociendo que es a la instrucción, a través de la escuela, a la que corresponde tal propósito.

Ahora bien, si el registro de la niñez en esos años se hará desde los parámetros de lo religioso-cívico-moral, en la medida en que se empieza a ver a los niños como ciudadanos modernos en ciernes comenzarán a surgir publicaciones dirigidas a ellos que expresan los modelos de comportamiento que formaban parte de los modos en que el mundo ilustrado se percibía a sí mismo. ${ }^{11}$

\section{MODELOS EJEMPLARES o MoZart PARA NiÑOS}

Ahora bien, ¿cuáles son las temáticas que se abordan en el $D N$ ? ¿Desde qué perspectiva? ¿De qué manera constituyen indicios de la infancia que se quiere impulsar? Se buscaba templar a la niñez con el ejemplo de personajes procedentes de distintos campos de la historia y de la literatura y evitar así narrativas fantásticas que confundían, según el pensamiento de la época, las mentes de los pequeños; el propósito, también por estas tierras, era inculcar modelos de virtud, moral y religión que propiciaran el recto comportamiento de estos niños a los que la patria, el Estado y la sociedad les pedirían su parte de trabajo, lealtad y devoción.

En lo particular, entre las temáticas que aborda el DN llama la atención el tratamiento que hace de lo biográfico con un sentido educativo, la manera en que responde a la imagen de cultura ilustrada y su visión del arte como indicio de los proyectos que circulaban en los ambientes letrados.

En relación con la biografía histórica como tal, puede decirse que atraviesa la Antigüedad clásica, el Medioevo, el Renacimiento, el
Barroco e incluso el Romanticismo, para llegar a nuestros días; aunque dotada de diferentes sentidos y orientaciones para la mentalidad de cada periodo, coincide en una intención de fondo: proponer modelos morales e instruir a sus lectores, a través de una pléyade de emperadores romanos, mártires y santos, cortesanos, artistas, guerreros y políticos. En el siglo XIX en particular, los atributos conferidos a los personajes que se proponen estarán mediados, además, por la perspectiva propia del Romanticismo, donde el modelo privilegiado es el del héroe reconocido por sus hazañas, por superar sus penurias y por su capacidad, carismática, de contribuir, de manera decisiva, a modelar el mundo.

Los proyectos educativos no escaparían a esta intención en la prensa infantil como publicación situada que se produce en un contexto y en un momento específicos, y que se interesa en formar a esos individuos niños que, en un breve periodo, habrán de convertirse en ciudadanos; qué mejor modelaje de la sensibilidad y el pensamiento puede ofrecerse que hacer accesibles las biografías ejemplares.

Aquí resulta interesante señalar que desde el movimiento de independencia hasta 1867 la enseñanza de la historia como tal estuvo ausente de la escuela de primeras letras; el rudimentario plan de estudios sólo incluía la enseñanza del catecismo religioso, moral y político en distintas versiones, que combinan virtudes morales, comportamiento urbano, conocimiento de deberes cívicos y, en el mejor de los casos, la historia sagrada (Meneses, 1983). Sólo hasta la reforma liberal de 1867, con la restauración de la República, se introdujeron los "Rudimentos de historia y geografía, especialmente de México” (Dublán y Lozano, 1876-1912: 156).

Ahora bien, los datos que ofrece Christine Thirion (1972) en "La presse pour les jeunes de 1815 à 1848 " nos permiten advertir similitudes de gran relevancia: además de la coincidencia

\footnotetext{
11 Un proceso similar se estaba llevando a cabo en Francia, donde la prensa infantil también tenía un propósito religioso, cívico y moral. Una y otra vez encontramos discusiones en torno a la importancia del amor por los padres, de duques virtuosos como el de Bourgoge y de la importancia de la fe, a tal grado que, en el Noveau mentor de l'adolescence et de la jeunesse (n. 6), De Geronval afirmaba, "La religion est le premier principe d'une bonne éducation" (Thirion, 1972: 11).
} 
temporal y del título de ambas publicaciones, conviene saber que este journal incluía, al final de cada mensualidad, una pequeña biografía de alguna celebridad que, a la manera de modelo ejemplar, pudiera instruir y moralizar a los niños. Por ejemplo, entre las biografías figura "Petit Napoleon", título que bien pudo haber sido la base del "Napoleoncito" publicado en el DN. Este dato resulta interesante debido a que la publicación data de los años de la derrota definitiva de Napoleón Bonaparte (1815) y la restauración de la monarquía borbónica.

Entre las biografías que aparecieron en el Diario de los Niños durante el escaso año que duró su publicación encontramos títulos como "Un episodio de la vida de Wolfgrand [sic.] Mozart" (1839), "Bruto" (1839); "Juana de Arco" (1839), "Bosquejo biográfico de Mirabeau" (1840); "Napoleoncito" (1840); "Educación y vida de María Estuardo" (1839) y "El Robinsoncito (1839), este último clara referencia al personaje literario que plantea la imagen del individuo que logra afrontar las adversidades y el rigor de la naturaleza. ${ }^{12}$

Queda claro que estas pequeñas biografías no siempre plantean personajes históricos y, en todo caso, la selección remite a los prototipos de la historia y cultura francesa e inglesa, sobre todo. Es interesante observar que poco a poco, en el contexto de posteriores publicaciones infantiles, los modelos importados se irán trasladando a temáticas más locales: hacia finales del porfiriato se introdujeron otras de corte más local, como Nezahualcóyotl, Cuauhtémoc, Hidalgo, Morelos y Juárez. En algunas de ellas se construyó la imagen del niño marginal que supera sus condiciones de vida, como lo fue Benito Juárez, el pastorcito indio que llegaría a ser presidente de la República; o bien la historia poco conocida de "Pepillo el arriero", relato que aborda y reelabora los orígenes de José María Morelos: un niño que transportaba con su tío mercancías del puerto de Acapulco, cuya "piedad filial jamás llegó a desmentirse” (Torres Quintero, 1910: 245). Pepito, aunque no fue cura desde un principio como su madre quería, a los 30 años decidió iniciar esos estudios en el Colegio de San Nicolás, en Valladolid, dirigido por el cura Miguel Hidalgo:

Aquel arriero convertido en cura bajo la influencia de su madre, y á una edad en que no es común decidirse por los estudios, se llamaba José María Morelos y Pavón, y la historia de México se enorgullece de contarlo entre sus héroes (Torres Quintero, 1910: 245).

En el tratamiento biográfico que se da a estos personajes podemos observar que ya está en proceso la conformación de lo que será una "historia de bronce", con su exaltación de los héroes y sus virtudes, los cuales hacen las veces de paradigma por alcanzar; en esta historia el personaje queda al centro, como protagonista único de sus propias hazañas y sus talentos llegan casi por generación propia o espontánea, como decimos hoy.

Ello es más claro en el caso de "Un episodio de la vida de Wolfgrand [sic] Mozart", donde la narrativa nos introduce en la extrema pobreza en que vivía el futuro genio y que lo acompañaría de por vida, en circunstancias difíciles, desoladoras, reto que trataría de superar a lo largo de toda la vida:

Reinaba la más profunda miseria en esta familia. Hacía un frio crudísimo, y no había siquiera un braserillo en que calentarse: los vestidos de los niños todavía no estaban muy maltratados; pero la casaca del padre se hallaba en un estado tal, que fácilmente se entreveía el forro (Diario de los Niños, I, 1839: 65).

El ambiente inicial no es muy distinto del que poco después encontraremos en las novelas románticas que caracterizarán a la literatura de la

12 En Francia, el libro de Defoe ya contaba con varias adaptaciones tales como Robinson suisse (1812), Robinson de douze ans (1818), Robinson des demoiselles (1834) y Robinson des glaces (1835). 
última mitad del siglo XIX, con personajes cuyo desarrollo se sobrepone a las situaciones de carácter económico en las que se hallan inmersos. Además, en este fragmento podemos ver la influencia de discusiones contemporáneas en torno a la naturaleza del espíritu humano: ¿será que una circunstancia como la pobreza determina la inclinación de un individuo hacia las malas acciones? Pues no, el Mozart de esta narración es una demostración de lo contrario.

\section{Figura 2. "Un episodio de la vida de Wolfgrand [sic.] Mozart”, 1839}

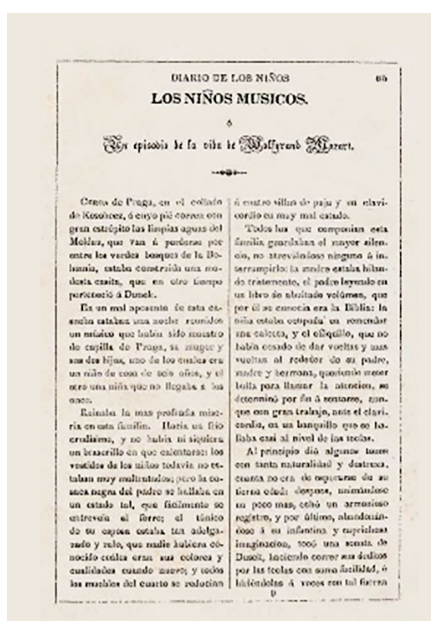

Fuente: Diario de los Niños I, Sección Los niños músicos, México, Imprenta de Miguel González, 1839, p. 65.

Así pues, en medio de las penurias familiares, mientras la madre tejía en silencio, su padre leía la Biblia y su hermana remendaba una calceta, actividades de lo que se percibía como propio de cada género, el Mozart de seis años finalmente decide sentarse en un banquito casi a la altura de las teclas del clavecín, y vaya maravilla que sucedió:

Al principio dio algunos tonos con tanta naturalidad y destreza, cuanta no era de esperarse de su tierna edad: después, animándose un poco más, echó un armonioso registro, y por último, abandonándose a su infantina y caprichosa imaginación, tocó una sonata de Dusek, haciendo correr sus deditos por las teclas con suma facilidad, é hiriéndolas á veces con tal fuerza que las vidrieras se estremecieron, yá veces con modulaciones tan expresivas que arrancaban lágrimas a los ojos de quienes las escuchaban (“Un episodio..., 1839: 65).

En este fragmento podemos observar que el genio de este pequeño músico no tiene un origen aparente: todo surge del poder creador de su "caprichosa imaginación", sin que nadie haya debido enseñarle con anterioridad lo que era un clavecín. Tal planteamiento encuadra perfectamente con la historia de los grandes individuos, de las hazañas heroicas, personales y autónomas de cualquier influencia externa, que en el específico caso de Mozart desconoce las horas que su padre había invertido en su formación en medio de una férrea disciplina. Se ignora la experiencia de su vida familiar, en la que se dan importantes procesos de trasmisión cultural a los que estuvo sometido en el curso de su infancia. Ni qué decir del padre de Wolfgang Amadeus, el gran Johann Georg Leopold Mozart, violinista, compositor y director muy logrado, maestro de capilla al servicio de la Corte del arzobispo de Salzburgo. En la presente historia del $D N$ el padre de Wolfgang Amadeus se nos presenta como un pobre "maestro de capilla" que porta una casaca raída y se limita a usufructuar el virtuosismo de sus hijos; ${ }^{13}$ se desconocen las opciones que tenían frente a sí los músicos de una época de transición entre su adscripción a los ámbitos de música religiosa y el mundo de la aristocracia cortesana (Santoni Rugiu, 1996).

El episodio también aporta elementos para aproximarnos a algunos problemas nodales de la cuestión artística que ya se perciben: nos enfrentamos a la experiencia estética que requiere de una actitud de escucha interior, silenciosa y concentrada - promovida por Kant en relación con el contacto con lo

13 Recordemos que el caso de los niños prodigio fue frecuente en la Europa de los siglos XVII y XVIII. 
sensible - que atravesará la práctica del concertismo en gestación. Se intuye lo que será la formación de las audiencias y los públicos modernos, fenómeno vinculado con la nueva sensibilidad y la formación del gusto de la sociedad cortesana del siglo XIX.

Volviendo a la imagen del joven Mozart que circuló en los medios parisino y mexicano a través de esta publicación vemos que, si bien descubre sus talentos, también siente hambre y pregunta por la cena, ante lo cual la madre "se levanta de su asiento para abrir un armario, de donde saca una rebanada de pan y la da a su hijo" ("Un episodio...", 1839: 66). Éste, con una generosidad muy cristiana, la comparte con su hermana y queda compungido al ver que los padres no tienen qué comer. Ante ello, Mozart le dice a Federica, su hermana, “ya que papá ha trabajado tanto por nosotros, trabajemos desde ahora para él" ("Un episodio...., 1839: 67); así se gestó la gira familiar por las principales cortes del centro de Europa (1761-1763) durante la cual lograron despertar el asombro y reconocimiento para el propio Mozart y para su hermana. ${ }^{14}$

El trabajo, propio de hombres virtuosos, se convierte así en una forma de dignificar el oficio de músico, en una sociedad ilustrada y en un proyecto de construcción de la República donde el artista busca un lugar digno, que le permita vivir decorosamente. El pequeño Mozart sí que sabía honrar a su padre y a su madre, de forma que, junto con su hermana, se proponen viajar tocando el clavecín y el violín para conseguir los ducados que tanta falta hacían en su casa.

Después de este acontecimiento, el cual no está del todo claro, sabemos que durante un concierto en la corte imperial de José II de Habsburgo el pequeño llega con "un vestido de paño con franjas de oro" ("Un episodio...", 1839: 70); su padre se había esmerado por inculcarle los usos de la vida cortesana. Pero, desde luego que el pequeño no sorprende sólo por su ropa, sino por sus talentos. Cuando su demostración concluye, en Viena, María Teresa, la madre del emperador, lo llama, pero en el camino Mozart cae y una hermosa joven lo levanta. Cuando el pequeño la ve, queda enamorado de ella, “¿Quélinda es V., señora! quiero casarme con V." (“Un episodio...", 1839: 71). Como era de esperarse, dicho amor no podrá realizarse, y no debido a la diferencia de edad, sino porque, "Esta dama á quien para sí escogía con tanta ingenuidad el niño Mozart, era la archiduquesa de Austria, la que habría de ser reina de Francia” (“Un episodio...", 1839: 71). De esta forma se integra otro elemento esencial a la narrativa de este joven genio: el amor imposible, que será una de las características esenciales del romanticismo en curso.

La historia termina con un diálogo que nos regresa a la virtud del amor filial que ha sido tan importante para la historia, y que será recurrente en otras narrativas similares. Cuando al joven Mozart le dicen que su padre estará muy feliz de ver a su hijo convertido en un gran músico, la archiduquesa le pregunta “iy tú estarás muy contento?”, a lo que el joven responde, "¿no he de estarlo si papá lo está?" (“Un episodio...", 1839: 72). Después sólo faltaba la moraleja: "pensando de este modo, hijos míos, es como un niño hace su carrera y logra su objetivo" ("Un episodio...", 1839: 72).

Así, el círculo se cierra en torno al impacto que la biografía de Mozart podría tener en el modelaje del comportamiento virtuoso de los niños, y habría que pensar también si a través de estos personajes históricos masculinos no se estaría privilegiando solamente el modelaje de los niños varones.

Ciertamente, la vida de Mozart, como aparece en el Diario de los Niños, deja una sensación de ingenuidad, así como falta de cohesión y de precisión de los datos históricos, pero debe tomarse en cuenta que la narrativa no desentona con los parámetros de veracidad de la época en que fue escrita, además de que no se pretendía escribir una biografía

${ }^{14}$ La información histórica sobre la biografía de Mozart procede de: https:/es.wikipedia.org/wiki/Wolfgang_ Amadeus_Mozart (consulta: 8 de junio de 2019). 
histórica propiamente dicha, sino un relato que frisa el lindero de la literatura.

Las contradicciones que encontramos en ella son propias de ese cruce entre moral laica y religiosa que fueron características de la primera mitad del siglo XIX: al mismo tiempo que está el deseo de confirmar la independencia del individuo en relación con las circunstancias que lo determinan, se nos presenta una moral católica que en ese entonces tuvo un gran peso, incluso en la facción liberal. Se trata, por lo demás, de una época de transición en gustos y sensibilidades, de exigencias referidas al oficio de músico que se debate entre su afiliación a la vida de la aristocracia cortesana o la pertenencia al servicio de la casa del príncipe, como un sirviente más.

Y sí, de cara a los datos históricos, la pregunta de rigor es si realmente conocieron en la Nueva España a Mozart. Pues bien, los músicos más famosos de la época, entre los que se contaba a Mozart, junto con Joseph Haydn (1732-1809), por distintas vías traspasaron los ambientes europeos y se interpretaron ampliamente en la Nueva España a horcajadas de los siglos XVIII y XIX. Se ubican en el tránsito del gusto por la música religiosa hacia la profana y marcan el surgimiento de una sensibilidad musical y una noción de gusto entre las élites mexicanas. Se sabe que hacia 1801, en plena efervescencia por las luchas independentistas, las partituras de Mozart se difundían a través del primer periódico del país:

En la Librería esquina de la calle de Santo Domingo y Tacuba, se vende una porción de música de Pleyel, Mozart, Kozeluc, Haydn, Cambini, Fordor, Vanhal, Rosetti, Hoffmeister, Boquerini y otros muchos autores, y también violines, guitarras y guitarrones, flautas, trompas y otros instrumentos (Gazeta de México, X, 31, 1801: 244). ${ }^{15}$

Lo anterior, junto con la gira que la familia Mozart hiciera (y que incluyó París, 1763), podría explicar el hecho de que la biografía de Mozart fuera una de las que se publicaron en los primeros artículos del $D N$.

\section{REPRESENTACIONES SOCIALES EN TORNO A LA NIÑEZ}

Resulta muy sugerente que en los años en que se publicó el $D N$ en los talleres de Vicente García Torres, también se publicó una obra que, desde mi punto de vista, resulta paralela y complementaria (Los niños pintados por ellos mismos, 1843), con propósitos análogos. Si bien ésta se refiere al medio europeo (la edición de I. Roix, antecedente inmediato de la mexicana, es de Madrid, 1841) permite rastrear las representaciones que la sociedad se hacía sobre la niñez. Es comprensible que lo que habría de definirse por infancia o niñez aún resultaba un concepto poco acotado, bastante laxo, que podía abarcar de 0 a 14 años de edad, aunque es evidente la intención por clasificar a la población, por ordenarla, distinguiéndola de la adultez a partir de sus propias características.

Los modos de pensar a la infancia y las descripciones que se hacen con respecto a lo que se percibe como sus actividades cotidianas, que circulará en estas obras, no son ajenos a la necesidad propia de aquellos tiempos de registrar y conservar tipos populares "mexicanos" que dieran cuenta de lo propio, de lo típico, de lo más característico de nuestra sociedad, que recién lograba su independencia; había una necesidad de reconocerse y diferenciarse de los otros. De hecho, esta práctica se inscribe en una tradición, en un movimiento más amplio conocido como costumbrismo, que emerge en el contexto del romanticismo, interesado en observar la realidad cotidiana y ofrecer cuadros de costumbres de sectores medios y acomodados. Este estilo fue incorporado por la Academia de Letrán (1836) en su propósito de impulsar una literatura de corte nacional,

${ }^{15}$ El subrayado es mío. El antecedente de la Gaceta de México de 1801 fue la Gazeta de México, primera publicación periódica fundada en el país en 1722. 
con lo cual se manifiesta la nueva sensibilidad de la época. Guillermo Prieto (1818-1897), uno de los impulsores del proyecto, marca la distancia del nuevo oficio de escritor en relación con los antecedentes:

...los círculos ilustrados que aun se extravían en el romanticismo pavoroso y se horrorizan ante las faltas al decoro del pueblo bajo o la cursilería de la clase media, deambulan curiosos e impertinentes por los vericuetos de la Ciudad de México para recoger - desde una perspectiva verista notable por su ímpetu festivo y crítico- el rumor de la vida, la agitación y los trapicheos de un heterogéneo repertorio de tipos (pollos y figurantas, léperos y calaveras, señoras y criadas, burócratas y petimetres), escenarios cotidianos (fisgones, vecindades, tertulias, paseos, ventorrillos)...(Prieto, 1845: 27).

Así surgieron obras como El periquillo Sarniento (1816), Los niños pintados por ellos mismos (1843) y Los mexicanos pintados por ellos mismos (1854-1855), en las cuales convergen literatura y litografía (Pérez Salas, 2005). Si bien es cierto que el costumbrismo, influido por la perspectiva del romanticismo, surgió en el terreno de la novela a través del empleo de voces populares, de la caracterización de tipos populares y cuadros de costumbres, también se desarrolló en publicaciones periódicas tempranas, como el Diario de México (18051817), que incluso llegó a incluir una sección denominada "Costumbres" (Martínez, 2000), siempre en la perspectiva de la búsqueda de lo propio, de la identidad. ${ }^{16}$

Los niños pintados por ellos mismos, versión mexicana de la publicación madrileña de 1841, es un indicio de la concepción del mundo en el momento que plantea una sociedad estructurada por clases sociales, ocupaciones e incluso limitaciones personales, en la medida en que su intención es

Describir la niñez en una serie de rasgos o artículos, cada uno de los cuales considera un niño en determinada profesión o clase de la sociedad; demostrar en ellos y hacer comprensible a la infantil inteligencia que en todos los estados es fácil, debido y útil observar las reglas de la sana moral, de la religión y de la buena crianza ("Advertencia preliminar", en Los niños pintados por ellos mismos, 1843: 4).

La publicación se integra con cuadros temáticos centrados en lo que se piensa que es un niño; en estos cuadros, a la imagen visual, plasmada en una litografía sigue una descripción, un relato moralizante, no exento de la dramaticidad propia del Romanticismo, en el que se destacan las virtudes del protagonista, pero también sus defectos (su posible incumplimiento con las expectativas que la familia había depositado en él), las penurias, los castigos y maltratos, la culpa y el arrepentimiento, o bien las lamentaciones por el destino que le tocó en suerte vivir, de todo lo cual deriva el consejo, la advertencia, la enseñanza (la laboriosidad, la perseverancia) y la moraleja (la compensación al comportamiento virtuoso). Dirigida a la población escolar, hay un esfuerzo por hacer de las lecciones un momento placentero, e incluso se recurre al uso de la "linterna mágica", como un apoyo visual para trasmitir los contenidos de manera agradable.

Pero ¿de qué niños estamos hablando?, ¿quiénes son los niños que se reflejan en esta obra?, ¿cómo se supone que se perciben en aquellos años tempranos del siglo XIX?, ¿cuáles son las divisiones del mundo social que habrían internalizado?

\footnotetext{
16 Reflejar a la sociedad a través de tipos representativos es una tradición que se venía ensayando, con distintos propósitos, en la plástica y en la literatura novohispanas (las pinturas de castas son ilustradoras al respecto); entre los siglos XVIII y XIX los artistas viajeros contribuyeron a fijar tipos al dibujar indios, considerados exóticos. Asimismo, los artesanos locales plasmaron en figuras de cera tipos y escenas populares. Son temáticas que nacieron al margen de la Academia de San Carlos, cuyo paradigma era el arte occidental, neoclásico. La labor de los escritores de la Academia de Letrán fue central para reorientar la mirada hacia lo que sucedía en la vida cotidiana en la propia región.
} 
Si bien ya circulaba la noción de infancia, aún no estaba claramente acotada. Se definía a los niños desde diversos atributos y ocupaciones que también podrían ser propios de otras edades de la vida y de distintos sectores sociales. Del panorama variopinto que se presenta, pueden distinguirse diversos grupos: el colegial, el escribiente y el instructor, pertenecientes al mundo letrado; los aprendices de distintos oficios propios de las artes mecánicas; los labradores, los leñadores y los pastores; los saltimbanquis, los cirqueros y los cómicos, vinculados con las artes de la calle (¿todos masculinos?). Pero también se incluye otra categoría que destaca por su mensaje fuertemente moralizante: los ciegos, los sordomudos, los mendigos y aun los expósitos (Los niños pintados por ellos mismos, 1843).

Ciertamente, se reflejan los tipos sociales conforme a los cuales se percibe la sociedad de su tiempo, pero, más que comunicar una realidad cotidiana, viva, plantean rasgos fijos, invariables, más próximos a las esencias que permanecen inamovibles en el curso del tiempo. Y así es como los niños harán propia una realidad fragmentada, sectorizada, con tajantes divisiones entre sí, pero resulta difícil imaginar que los supuestos lectores de NP, a su vez, hubieran conocido esta última obra; es difícil saber en qué medios circuló. Lo que sí es clara es la intención del editor de poner en circulación títulos que abonaran al despliegue del incipiente mundo de las obras dirigidas a la niñez mexicana en la perspectiva de difundir la instrucción, como forma de lograr el progreso social. Otro dato que no se debe escapar es que un año después, en 1844, también auspiciada por el editor García Torres y con la autoría de Alexander de Saillet, se publicó Las niñas pintadas por ellas mismas, donde se consagra el ser femenino que dominaría la época.

\section{A MODO DE CIERRE}

Puede decirse que ambas publicaciones, el Diario de los Niños y Los niños pintados por ellos mismos, cada una por su parte, se dirigen al universo de la niñez mexicana con una intención educativa, instructiva, a partir de la cual los editores proyectan el modelaje del comportamiento de los nuevos ciudadanos que requería la modernidad en el contexto de los procesos de secularización y de búsqueda del progreso. De esta manera se marcaban las políticas de la época.

En este artículo, la aproximación a ambos textos fundamentalmente se ha hecho como indicios de las representaciones sociales en boga entre el sector ilustrado, así como de los recursos que se echaron a andar para ello a partir de distintas narrativas, ya sea el género biográfico, o los relatos que dan cuenta de la forma en que, se supone, los niños experimentan distintas actividades y ocupaciones; $\mathrm{O}$ las litografías que, a la vez, dan cuenta de los avances de la imprenta e inciden en la educación de la mirada. La niñez como tal adquiriría nuevas formas de clasificación social y, de paso, de su posible inserción en ellas.

En el caso de los relatos de Los niños pintados por ellos mismos llama la atención la problemática social que estaba aflorando, ya que se tocan tangencialmente zonas de penumbra apenas sugeridas donde está presente el mal y la necesidad de corregirlo.

Son esos años - mediados del siglo XIXdonde se expresa la preocupación por la emergencia de múltiples problemas sociales y comportamientos indeseables de degradación moral, de perversión de las costumbres que daban lugar a todo tipo de atropellos: estamos frente a la criminalización de la pobreza extrema que hacía necesarias medidas de 
limpieza social con instituciones ad hoc como los hospitales, hospicios y asilos, y normativas contra la vagancia, la mendicidad, el hurto y la ociosidad, así como el establecimiento de formas diversas de vigilancia. ${ }^{17}$ Lo anterior reglamentado a través de leyes y disposiciones que comenzaron a emitirse desde las primeras décadas del siglo XIX, alrededor de 1828, y del establecimiento de las casas de corrección, en torno a 1840 (Gramigna, 1998; Sánchez, 2003; Staples, 2005), que constituyeron la otra cara de la moneda de la niñez candorosa, inocente, obediente, dócil, respetuosa de la autoridad, de buenas maneras, laboriosa y civilizada.
Serán estas formas de percepción de la propia sociedad las que darán sustento, a su vez, a nuevas prácticas sociales que desembocarán en otras formas de institucionalidad y control social.

Finalmente, sería desde estas representaciones sociales y desde estas realidades como la educación-instrucción-escuela primaria devino lo que se pensaba que sería la panacea para superar todos los males sociales y encauzar a la niñez mexicana hacia el progreso, meta ambicionada por los ilustrados del siglo XIX, motor de las políticas educativas y culturales de la modernidad.

\section{REFERENCIAS}

Agostini, Claudia (2015), "Divertir e instruir. Revistas infantiles del siglo XIX mexicano", en Belem Clark de Lara y Elisa Speckman de Guerra (eds.), La República de las Letras. Asomos a la cultura escrita del México decimonónico, II, México, UNAM-Instituto de Investigaciones Bibliográficas, pp. 171-182.

Aguirre, María Esther y Aldo Mier (2015), "Sobre el tratamiento biográfico en el Diario de los niños (1839-1840)", Correo del Maestro, vol. 19, núm. 224, pp. 22-32.

Alcubierre Moya, Beatriz (2005), Ciudadanos del futuro. Una historia de las publicaciones para niños en el siglo XIX mexicano, México, COLMEX/UAEM.

“Bosquejo biográfico de Mirabeau” (1840), Diario de los Niños. Literatura, entretenimiento e instrucción, vol. II, México, Imprenta de Miguel González.

Briggs, Assa y Patricia Clavin (1997), "Orden y movimiento, 1815-1848”, en Assa Briggs y Patricia Calvin (eds.), Historia contemporánea de Europa 1789-1989, Barcelona, Crítica, pp. 53-92.

"Bruto" (1839), Diario de los Niños. Literatura, entretenimiento e instrucción, vol. I, México, Imprenta de Miguel González.

Burke, Peter (2006), ¿Qué es la historia cultural?, Barcelona, Paidós.

CAMARILlo Camargo, María Teresa eIrmaLombardo García (1984), La prensa en México, siglo XIX, México, UNAM-Instituto de Investigaciones Bibliográficas.
Cardona, Giorgio Raimondo (1994), Antropología de la escritura, Barcelona, Gedisa.

CASTAÑEDA, Carmen (2002), Del autor al lector, vol. I: Historia del libro en México, vol. II: Historia del libro, México, CIESAS.

Castillo Gómez, Antonio (1995), “Cultura escrita y mundo editorial (En torno al nacimiento de la colección LEA)", Signo. Revista de Historia de la Cultura Escrita, núm. 2, pp. 213-216.

Castro, Miguel Ángel y Guadalupe Curiel (2000), Publicaciones periódicas mexicanas del siglo XIX: 1822-1855. Fondo Antiguo de la $\mathrm{He}$ meroteca Nacional y Fondo Reservado de la Biblioteca Nacional de México (colección Lafragua), México, UNAM.

Chartier, Roger (2005a), El mundo como representación. Estudios de historia cultural, Barcelona, Gedisa.

Chartier, Roger (2005b), El pasado del presente. Escritura de la historia, historia de lo escrito, México, Universidad Iberoamericana.

Diario de los niños. Literatura, entretenimiento e instrucción, vol. I (1839), México, Imprenta de Miguel González.

Diario de los niños. Literatura, entretenimiento e instrucción, vols. II y III (1840), México, Imprenta de Vicente García Torres.

Dublán, Manuel y José María Lozano (1876-1912), Legislación mexicana o colección completa de las disposiciones legislativas expedidas desde la Independencia de la República, tomo X: 1867-1869, México, Imprenta del Comercio.

17 Desde el siglo XVI ya hay antecedentes de este tipo de preocupaciones y de planteamientos, enraizados en la caridad cristiana, en la actitud piadosa de socorrer a los más necesitados. Juan Luis Vives, el humanista español interesado en la educación escribió el Tratado del socorro de los pobres (1526) con ese sentido, a la vez que propuso medidas estrictas contra los viciosos. Puede profundizarse en Martin (1985). 
"Educación y vida de María Estuardo" (1839), Diario de los Niños. Literatura, entretenimiento e instrucción, vol. I, México, Imprenta de Miguel González.

"El Robinsoncito" (1839), Diario de los Niños. Literatura, entretenimiento e instrucción, vol. I, México, Imprenta de Miguel González.

Gimeno de Flacquer, Concepción (1883-1890), El álbum de la mujer, México, Imprenta Francisco Díaz de León.

Galván de Terrazas, Luz Elena (1998), “El Álbum de los Niños. Un periódico infantil del siglo XIX", Revista Mexicana de Investigación Educativa, vol. 3, núm. 6, pp. 301-316.

Gazeta de México, vol. X, núm. 31 (1801), México, Don Felipe de Zúñiga y Ontiveros.

Gramigna, Anita (1998), Storia della mala educazione. I bambini cattivi nel secolo XIX, Bologna, CLUEB.

"Juan Wenceslao Sánchez de la Barquera" (1910), en Justo Sierra, Luis G. Urbina, Pedro Henríquez Ureña y Nicolás Rangel, Antología del Centenario. Estudio documentado de la literatura mexicana durante el primer siglo de Independencia, vol. 4, México, Ministerio de Instrucción Pública y Bellas Artes, pp. 227-331.

"Juana de Arco" (1839), Diario de los Niños. Literatura, entretenimiento e instrucción, vol. I, México, Imprenta de Miguel González.

Los niños pintados por ellos mismos (1843), adaptación al español de Manuel Benito Aguirre, México, Imprenta de Vicente García Torres.

Martin, Norman Francis (1985), "Pobres, mendigos y vagabundos en la Nueva España, 1702-1766: antecedentes y soluciones presentadas", Estudios de Historia Novohispana, vol. 8, núm. 8, pp. 99-126. DOI: https://doi.org/10.22201/iih.24 486922e.1985.008.3285

Martínez Luna, Esther (2000), “Costumbrismo ilustrado en El Diario de México: antecedentes en México de los cuadros de costumbres”, en José Quiñones Melgoza (ed.), Memoria del Primer Coloquio Letras de la Nueva España, México, UNAM-Instituto de Investigaciones Filológicas, pp. 128-140.

Meneses Morales, Ernesto (1983), Tendencias educativas oficiales en México, 1821-1911, México, Porrúa.

Mondragón Contreras, Jimena (2008), "Una historia para una infancia. El discurso histórico en publicaciones periódicas infantiles a finales del siglo XIX en México", Boletín del Instituto de Investigaciones Bibliográficas, vol. 13, núm. 1-2, pp. 157-178.

"Napoleoncito" (1840), Diario de los Niños. Literatura, entretenimiento e instrucción, vol. II, México, Imprenta de Miguel González.
Nava Martínez, Othón (2002), “Origen y desarrollo de una empresa editorial: Vicente García Torres, 1838-1841", en Laura Suárez de la Torre (ed.), Empresa y cultura en tinta y papel 1800-1860, México, Instituto Mora/UNAM-IIB, pp. 123-130.

PÉrez Salas, María Esther (2005), Costumbrismo y litografía en México: un nuevo modo de ver, México, UNAM-Instituto de Investigaciones Estéticas.

Pérez Vejo, Tomás (2001), “La invención de una nación: la imagen de México en la prensa ilustrada de la primera mitad del siglo XIX", en Laura Suárez de la Torre y Miguel Ángel Castro (eds.), Empresa y cultura en tinta y papel (1800-1860), México, UNAM-Instituto de Investigaciones Bibliográficas, pp. 395-408.

Prieto, Guillermo (1845), "Literatura nacional", Revista Científica y Literaria de México, tomo I, pp. 27-29.

"Prólogo" (1839), en Diario de los Niños. Literatura, entretenimiento e instrucción, vol. I, México, Imprenta de Miguel González, p. 1.

"Prospecto" (1839), en Diario de los Niños. Literatura, entretenimiento e instrucción, vol. I, México, Imprenta de Miguel González, p. 3.

Rıoux, Jean-Pierre y Jean-François Sirinelli (1999), Para una historia cultural, México, Taurus.

Ruiz Castañeda, María del Carmen y Luis Reed Torres (coords.) (1974), El periodismo en México: 450 años de historia, México, Tradición.

SÁnCHez Mayor, Hilda Margarita (2003), "La percepción sobre el niño en el México moderno (1810-1930)", Tramas, núm. 20, pp. 33-59.

Santoni Rugiu, Antonio (1996), Nostalgia del maestro artesano, México, UNAM-CESU/Miguel Ángel Porrúa.

Staples, Anne (2005), Recuento de una batalla inconclusa. La educación mexicana de Iturbide a Juárez, México, El Colegio de México.

SuÁrez de la Torre, Laura (coord.) (2003), Constructores de un cambio cultural: impresores-editores y libreros en la ciudad de México, 1830-1855, México, Instituto Mora.

Thirion, Christine (1972), "La presse pour les jeunes de 1815 à 1848”, Bulletin des Bibliothèques de France, en: http://bbf.enssib.fr/consulter/bbf-197203-0111-002 (consulta: 16 de junio de 2020).

Torres Quintero, Gregorio (1910), "Historia patria. Pepito el arriero", La enseñanza primaria, México, Colegio de Profesores Normalistas de México, pp. 244-245.

"Un episodio de la vida de Wolfgrand [sic] Mozart" (1839), Diario de los Niños, vol. I, México, Imprenta de Miguel González, pp. 65-73.

Wright, Laureana y Mateana Murguía (1887-1889), Violetas del Anáhuac. Periódico literario redactado por Señoras, México, Imprenta de Aguilar e Hijos. 
Figura 3. Imágenes de Los niños pintados por ellos mismos, imprenta de Vicente García Torres

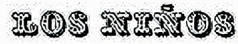

3)

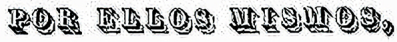

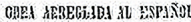

park

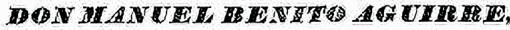

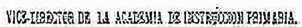

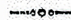

PEBUICALA BN MExico

露icente

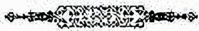

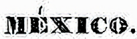

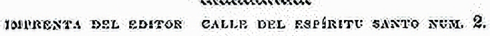
Leas.

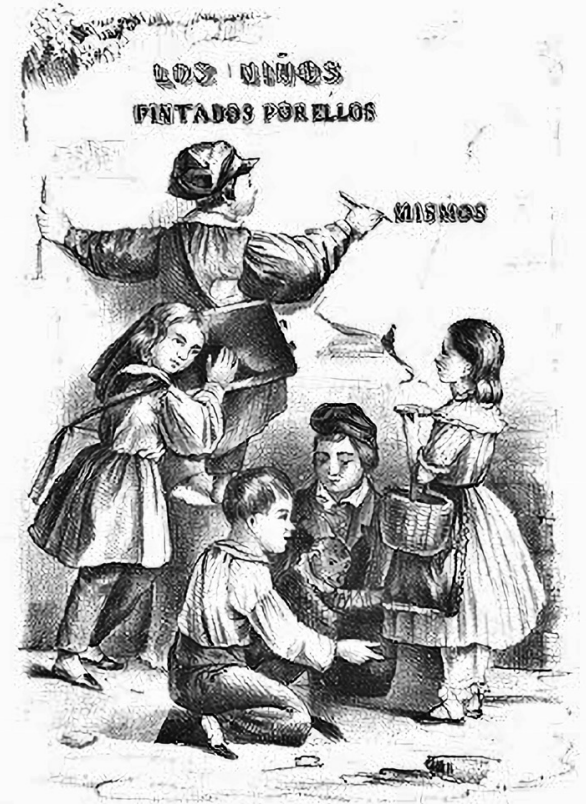




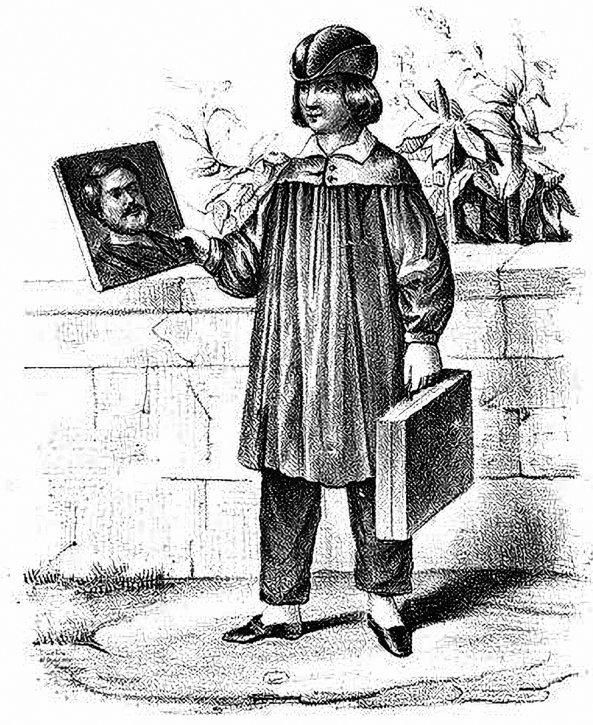

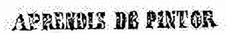

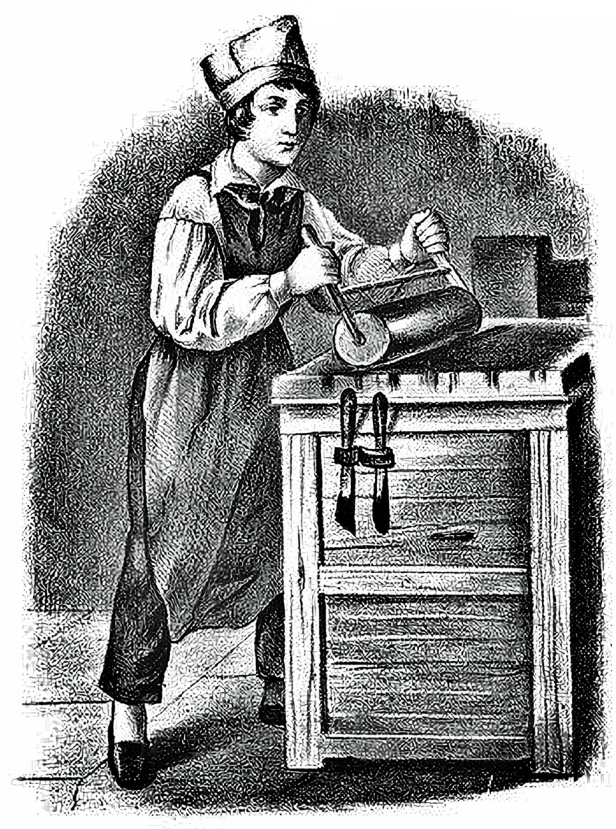

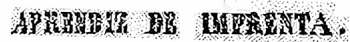

Fuente: Los niños pintados por ellos mismos (1843), portada; contraportada; “Aprendiz de pintor", p. 19; "Aprendiz de imprenta", p. 28. 